\title{
PLANALTO NORTE CATARINENSE: ALGUMAS CONSIDERAÇÕES SOBRE ASPECTOS HISTÓRICOS, CARACTERÍSTICAS FÍSICO-NATURAIS E EXTRATIVISMO
}

\author{
Alexandre Assis Tomporoski ${ }^{1}$ \\ Jairo Marchesan ${ }^{2}$
}

\begin{abstract}
RESUMO
O objetivo deste artigo consiste em compreender, a partir da apresentação dos principais aspectos pertinentes à história e às características físico-naturais do Planalto Norte Catarinense, o processo histórico relacionado ao extrativismo vegetal, deflagrado nas primeiras décadas do século XX, no território sob análise. Com este intuito, adota-se uma metodologia que busca integrar ambos os enfoques, ou seja, sob o enfoque da história, procura-se entender como ocorreu a extraordinária intensificação do processo extrativista, e, sob o enfoque das características físico-naturais, as motivações, os atributos que contribuíram para a incidência do referido processo. O principal resultado, proveniente da aplicação desta metodologia, é o entendimento sobre as origens da exploração maciça das florestas nativas, decorrente da inserção do capital estrangeiro, manifestadamente da Southern Brazil Lumber and Colonization Company, maior serraria em atividade na América do Sul, que durante o período de 1910-1940 explorou impiedosamente a opulente Mata de Araucárias que predominava no território, da qual, hodiernamente, permanecem remanescentes da formação original. Conclui-se que, não obstante o término das atividades operacionais da Lumber Company, guardadas as devidas adaptações, o processo extrativista perpetuou-se no território, através da inserção, a partir da década de 1960, de espécies exóticas de árvores, tal qual o pinus illiotti. Dentre as consequências atuais da prevalência do processo extrativista, encontrase a demanda crescente por áreas de terras visando os reflorestamentos, em detrimento da utilização dos solos para diversificação da produção e desenvolvimento sustentável do território.
\end{abstract}

Palavras-chave: Planalto Norte Catarinense. História. Lumber Company. Extrativismo. Desenvolvimento Regional.

\footnotetext{
${ }^{1}$ Graduado e Doutor em História, com atuação no Programa de Mestrado em Desenvolvimento Regional da Universidade do Contestado (UnC) - Santa Catarina. Brasil. E-mail: assis.historia@gmail.com

${ }^{2}$ Graduado e Doutor em Geografia, com atuação no Programa de Mestrado em Desenvolvimento Regional da UnC. Santa Catarina. Brasil. E-mail: jairo@unc.br
} 


\section{ABSTRACT \\ NORTH REGION OF SANTA CATARINA: SOME CONSIDERATIONS ABOUT ITS HISTORIAL ASPECTS, PHYSICAL AND NATURAL FEATURES AND EXTRACTIVISM}

The purpose of this article is to understand, from the presentation of the main aspects of the history and the physical and natural features of North Region of Santa Catarina, the historical process related to the vegetal extraction, started in the first decades of the twentieth century, in the territory under analysis. To this, we adopt a methodology that seeks to integrate both approaches, that is, from the standpoint of History, seeks to understand how occurred the extraordinary intensification of the extraction process, and from the standpoint of physical and natural characteristics, the motivations and attributes that contributed to the incidence of that process. The main result from the application of this methodology is the understanding of the origins of the massive exploitation of native forests, due to the insertion of foreign capital, manifestly from Southern Brazil Lumber and Colonization Company, the largest sawmill in activity in South America, which during the period 1910-1940 ruthlessly exploited the opulent Araucaria Forest that predominated in the territory, which, in our times, there are a few remnants of the original formation. We conclude that, despite the completion of the operational activities of Lumber Company, bearing in mind the respective proportions, the extraction process was perpetuated in the territory, by inserting, at the end of the 1960s, exotic tree species, like the pinus illiotti. Among the current consequences of the prevalence of extractive process, is the growing demand for land areas targeting reforestation, to the detriment of land use for diversification of agricultural production and sustainable development of the territory.

Keywords: North Region of Santa Catarina. History. Lumber Company. Extractive. Regional Development.

\section{INTRODUÇÃO}

Neste artigo, a abordagem considera os principais aspectos históricos que caracterizam o território do Planalto Norte Catarinense, e focaliza em algumas características físiconaturais selecionadas, com o intuito de embasar o argumento sobre o processo de desenvolvimento caracterizado pelo extrativismo de produção, que historicamente ocorreu na região.

Dada a preponderância para a argumentação, convém destacar que o texto amplia o exame dos aspectos históricos do território, em detrimento de uma exposição mais sucinta das características físico-naturais. Resulta de revisão da literatura e sua releitura.

Eis que, assim procedendo, ou seja, analisando conjuntamente aspectos históricos e características físico-naturais obtém-se uma perspectiva inter-relacional sobre o desencadeamento do extrativismo de produção no território do Planalto Norte Catarinense. No que tange as características físico-naturais, destaca-se a formação vegetal no território, isto é, as opulentes florestas, incluídas na Mata de Araucárias, que outrora predominavam, fato que atraiu o capital estrangeiro a explorá-las, mediante a instalação, no início do século XX, da maior serraria em operação no continente sul americano. 
Portanto, com o fim de explorar as abundantes florestas do território, a Southern Brazil Lumber and Colonization Company operou durante décadas, até sua estatização, em 1940, e posterior desativação em meados da década de 1950.

Não obstante esse processo histórico de extrativismo das florestas nativas, em fins da década de 1960, a introdução de espécies exóticas contribuiu para a permanência do processo extrativista, e perpetuou-se mediante o reflorestamento de milhares de hectares com árvores pinus illiottii. As áreas reflorestadas visam atender, principalmente, a demanda por matériaprima das indústrias de papel e celulose - muitas das quais controladas pelo capital estrangeiro - impossibilitando a utilização destas áreas em prol do desenvolvimento sustentável, e, assim, amenizar as históricas desigualdades sociais neste território.

Este texto, além da introdução, inicia pela delimitação da área em estudo, seguindo pela sua caracterização histórica e físico-natural. Na sequência, fazemos algumas análises, caracterizando o caráter extrativista da economia regional, o que é complementado nas considerações finais.

\section{DELIMITAÇÃO DA ÁREA DE ABRANGÊNCIA DO PLANALTO NORTE CATARINENSE}

Com o intuito de estabelecer a localização do território sob análise, inicialmente convém delimitar a sua área de abrangência. O Planalto Norte Catarinense possui uma área territorial de $11.041,365 \mathrm{~km}^{2}$ (onze mil, quarenta e um vírgula trezentos e sessenta e cinco quilômetros quadrados), representando $11,58 \%$ (onze inteiros e cinquenta e oito centésimos por cento) da área territorial do estado de Santa Catarina, e é constituído por 13 (treze) municípios, a seguir enumerados, em ordem alfabética: Bela Vista do Toldo, Campo Alegre, Canoinhas, Irineópolis, Itaiópolis, Mafra, Major Vieira, Monte Castelo, Papanduva, Porto União, Rio Negrinho, São Bento do Sul, Três Barras. Na Figura 01, é possível visualizar a localização do território do Planalto Norte Catarinense sob a perspectiva do Estado de Santa Catarina e da República Federativa do Brasil. 
Figura 1 - Localização dos municípios inseridos no território do Planalto Norte Catarinense

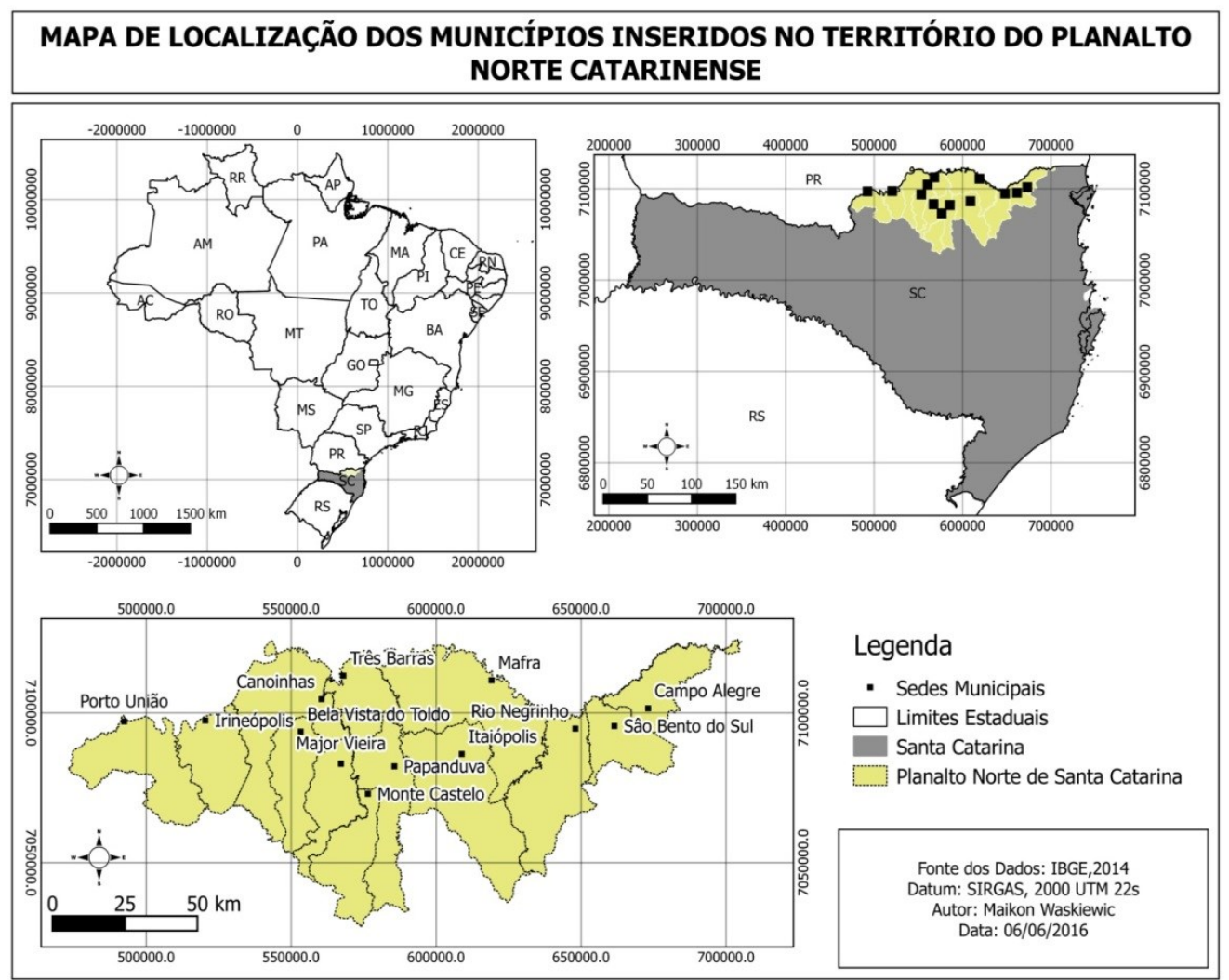

Fonte: IBGE (2014)

\section{ASPECTOS HISTÓRICOS DO PLANALTO NORTE CATARINENSE}

Em seus primórdios, o Planalto Norte Catarinense fora habitado por grupos humanos indígenas, especificamente das tribos Xoklengs e Kaingangs.

Este cenário transformou-se drasticamente a partir do ano de 1728, quando ocorreu a abertura da Estrada de Tropas, caminho que interligava os estados do Rio Grande do Sul e São Paulo, o que propiciou o início do processo de povoamento da região. Cabe destacar que, em sua longa jornada, transportando produtos e animais (gados vacum, cavalar e muar) comercializados principalmente na feira de Sorocaba (São Paulo), os tropeiros necessitavam realizar paradas para descanso e alimentação (SUPRINYAK, 2008).

Nestes locais de parada, ao longo do Caminho de Tropas, gradativamente foram surgindo povoados, que mais tarde originaram alguns dos municípios que atualmente integram o Planalto Norte Catarinense. Este caminho permaneceu em atividade até o início do século XIX.

Além do Caminho de Tropas, outro fator preponderante para o povoamento da região consistiu na chegada dos imigrantes, oriundos precipuamente do continente europeu. $\mathrm{O}$ ano de 1829 registra a chegada dos primeiros imigrantes, de origem alemã, ao município de Rio Negro (PR). 
Subsequentemente, sucessivas levas de imigrantes adentraram a região, e, a partir dos anos 1890, acentuou-se sobremaneira a chegada de imigrantes provenientes de diversos países europeus, destacando-se aqueles de nacionalidade alemã, polonesa e ucraniana.

Conforme analisado em Tomporoski (2013), durante o processo de ocupação do Planalto Norte Catarinense, ocorreu a formação de bairros rurais, ou seja, um conjunto de famílias que mantinham conexão entre si, embora a proximidade das residências não correspondesse a elemento de imprescindibilidade. De fato, as habitações que compunham determinado bairro rural poderiam estar tão afastadas umas das outras que dificilmente cogitar-se-ia que formariam um bairro rural. Portanto, surge a indagação: quais atributos poderiam gerar vínculos de convivência entre famílias ou grupos de famílias situadas a distâncias relativamente longas? A resposta consiste na necessidade de auxílio mútuo para as tarefas vultosas e urgentes, tais como colheitas e roçadas. Por conseguinte, também ocorria o compartilhamento dos momentos lúdicos e religiosos (MELLO e SOUZA, 2001).

A partir da formação dos bairros rurais, suscitava um sentimento de pertencimento a algo maior, uma união de pessoas em prol da coletividade, no qual se fortaleciam costumes que propiciavam relações solidárias entre seus habitantes. Neste contexto, destacam-se as práticas laborais relacionadas à roça cabocla, à criação comunal de animais e, precipuamente, ao pixirum. Analogamente, práticas religiosas também se consolidavam, sobressaindo-se a devoção a São João Maria e as festas religiosas (TOMPOROSKI, 2015).

Acerca dos costumes provenientes das práticas laborais, cabe destacar o pixirum, que consistia em uma reunião de trabalho, um mutirão, desprovido de quaisquer relações pecuniárias. Para a execução de atividades vultosas, cuja morosidade, dadas as condições climáticas, implicava em perdas, urgia a conclusão da tarefa, o que somente seria viável se o morador do bairro rural convocasse seus vizinhos para ajudá-lo. Caso quem convocasse possuísse atributo de legitimidade, o chamado seria imediatamente atendido. Posteriormente, aquele que convocou permanecia com a obrigação moral de retribuir a ajuda recebida, procedendo de modo semelhante quando no porvir fosse convocado, fortalecendo sobremaneira as relações de solidariedade naquele contexto.

No território do Planalto Norte Catarinense, também irrompeu o coronelismo ${ }^{3}$, fenômeno através do qual, fazendeiros e comerciantes, proprietários de grandes latifúndios, exerciam influência sobre o poder político local. Essa influência política advinha não somente do latifúndio e da correspondente riqueza que o mesmo poderia gerar, mas, também, do contingente de agregados que residiam no entorno da propriedade, representados pelos peões, homens de confiança e pelos fazendeiros de menor expressão, posseiros e lavradores dos arredores, que ofereciam apoio e lealdade ao coronel. Essa capacidade de dispor de significado contingente de homens proporcionava ao coronel a possibilidade de exercer funções de polícia, acentuando ainda mais seu domínio.

\footnotetext{
${ }^{3}$ O termo "coronel" vem da extinta guarda nacional imperial, que lutou nas guerras do Prata, do Uruguai e do Paraguai, entre os anos de 1851 a 1870, convertendo-se em termo meramente decorativo após as mencionadas guerras e abolido na Primeira República. No Império, cada município possuía um regimento da guarda nacional, o posto de "coronel" era concedido ou vendido ao chefe político deste município, que normalmente era o mais rico comerciante, industrial ou fazendeiro (MACHADO, 2004, p. 93 ).
} 
Entretanto, com o advento da República, ocorreu o fortalecimento do poder político local, exercido pelos mandatários legitimamente eleitos, implicando na gradativa decadência da influência política dos coronéis.

A partir da vigência lei $n^{\circ}$ 601, de 18 de setembro de 1850, sancionada por Dom Pedro II, conhecida como a "Lei de Terras", houve uma transformação paulatina na relação entre os coronéis e a população cabocla. A Lei de Terras, na tentativa de organizar a propriedade privada no Brasil, acabou por privilegiar os grandes fazendeiros e proprietários de latifúndios, pois, com a legitimação da propriedade, as maiores e melhores áreas que haviam sido obtidas através da posse, permaneceram sob controle dos grandes fazendeiros. Estes, com o decorrer do tempo, passaram a proibir o acesso dos caboclos aos ervais nativos de suas propriedades, restringindo-os de recursos anteriormente disponíveis. Entrementes, a coleta da erva-mate correspondia a um recurso importante para subsistência do caboclo.

Não obstante a atuação dos coronéis, o advento e a inserção do capital estrangeiro, a partir da primeira década do século XX, contribuiu decisivamente para concentração da propriedade privada, e, por conseguinte, para o agravamento da tensão social.

Com o objetivo de construir uma ferrovia que interligasse os estados do sul do Brasil, o governo brasileiro assinou um contrato com a Brazil Railway Company, companhia responsável pela construção de rede ferroviária, tendo como pontos de partida e de chegada as cidades de Itararé em São Paulo e de Santa Maria, no Rio Grande do Sul. No ano 1910, foi concluída a construção do trecho que atravessava o território catarinense, num total de trezentos e oitenta quilômetros, entre a cidade de União da Vitória, no Paraná, e Marcelino Ramos, no Rio Grande do Sul, às margens do rio Uruguai.

Todavia, o contrato para a construção da ferrovia estabelecia que a empresa responsável pela empreitada - a Brazil Railway Company - teria o direito de explorar as terras adjacentes à linha tronco, numa extensão de até quinze quilômetros do leito da linha férrea. Essas terras eram cobertas por milhões de pinheiros ou araucárias, imbuias, canelas pretas, cedros e cabriúvas. Objetivando extrair e comercializar essa madeira de alto valor econômico e, mais tarde, vender parte daquelas terras a imigrantes europeus, foi constituída uma subsidiária da Brazil Railway Company, a Southern Brazil Lumber and Colonization Company. Em 1910, a Lumber instalou em Três Barras, então território paranaense contestado por Santa Catarina, uma moderna serraria. A empresa instituiu um processo industrial altamente mecanizado, com elevada organização técnica, tornando-se a maior madeireira da América do Sul (CARVALHO, 2010).

Com o avanço de suas atividades, a empresa instaurou um incisivo processo de expansão fundiária, em muitos casos utilizando-se de seu corpo de segurança (contingente de homens armados) para obter as terras desejadas. Além disso, o processo fabril, iniciado em meio à mata, através do arraste das árvores tombadas por guinchos, dentre as quais pinheiros araucárias, imbuias, canelas pretas, cedros e cabriúvas, destruia toda a vegetação existente no percurso, ou seja, árvores menores, espécies economicamente menos interessantes e também grandes quantidades de árvores de erva-mate, cuja extração, como já relatado, consistia em recurso preponderante para a sobrevivência da população pobre que habitava a região.

Portanto, naquele contexto, caracterizado pelo controle da terra exercido pelos grandes proprietários de latifúndios, ou seja, os coronéis, e, concomitantemente pelo capital 
estrangeiro, representado pela Brazil Railway Company e sua subsidiária, a Lumber Company, a situação da população cabocla, formada por pequenos posseiros e sitiantes, tornara-se insustentável, dada a privatização da terra, especialmente em decorrência da proibição de exploração da erva-mate. Esse processo de exclusão e marginalização contribuiu para a adesão dos caboclos aos redutos e influenciou peremptoriamente a deflagração do movimento sertanejo do Contestado (1912-1916), comumente denominado Guerra do Contestado.

Embora a disputa entre os estados do Paraná e de Santa Catarina - a Questão de Limites - tenha assumido, durante muito tempo, a condição de causa principal para a eclosão da Guerra do Contestado, o avanço das pesquisas explicitou uma diversidade de motivações e de objetivos, conforme a região da zona contestada e dos setores sociais que aderiram ao movimento. Machado (2004, p. 259) assim as sintetiza:

\begin{abstract}
Para os habitantes de Taquaruçu e Perdizes, locais de origem do movimento, a rebelião foi o caminho trilhado após a violência que os coronéis e o governo, em sua totalidade, haviam praticado contra o monge José Maria. Para os sitiantes e posseiros dos vales do Timbó, Tamanduá e Paciência, era um meio de combater a presença cada vez mais agressiva dos coronéis Fabrício Vieira e Arthur de Paulo e Souza, que desejavam estender suas propriedades e sua influência política sobre aquelas regiões. Para as oposições políticas formais aos chefes municipais de Curitibanos e Canoinhas, significava uma oportunidade ímpar de minar o poder do coronel Albuquerque e do Major Vieira. Para os antigos maragatos de todo o planalto, a 'guerra santa' significava a volta à ativa e uma chance de desforra contra os pica-paus.
\end{abstract}

No caso específico do Planalto Norte Catarinense, a adesão ao movimento foi influenciada, principalmente, pelos seguintes fatores: a luta em prol do cumprimento da sentença referente à disputa por limites entre os estados do Paraná e Santa Catarina; o embate entre posseiros, sitiantes e mesmo proprietários de maior vulto contra a ferrovia e a Lumber Company, em particular, ao domínio e às injustiças praticadas pela Lumber Company, que expulsou milhares de posseiros dos vales dos rios Negro e Iguaçu.

Em suma, a luta contra o capital estrangeiro, o domínio político e fundiário dos coronéis, a exclusão da população nacional em detrimento do assentamento de estrangeiros, as injustiças praticadas por aqueles que ocupavam cargos nos governos municipal, estadual e federal, representaram os principais motivos para os rebeldes ingressarem nas trincheiras do movimento sertanejo do Contestado.

\title{
ALGUMAS CARACTERÍSTICAS FÍSICO-NATURAIS DO PLANALTO NORTE CATARINENSE
}

A apresentação das principais características físico-naturais pertinentes ao Planalto Norte Catarinense, mediante descrição das formações geológica, hidrográfica e vegetal, decorre, a priori, da necessidade de se conhecer os atributos inerentes à formação vegetal predominante no território, para o fim de auxiliar na compreensão das motivações que conduziram, a partir do início do século XX, ao processo produtivo pautado no extrativismo, ainda vigente, que exerce influência sobre o desenvolvimento regional. 
Inicialmente, faz-se necessário apresentar as características da formação geológica. Conforme Loczy (1980), o território do Planalto Norte Catarinense vincula-se à formação da Bacia do Paraná, a qual se estende por uma área de aproximadamente $1.600 .000 \mathrm{~km}^{2}$ (hum milhão e seiscentos mil quilômetros quadrados). Trata-se de uma complexa fossa tectônica, assumindo forma elipsoidal, com eixo maior apontando na direção NNE - SSW, e encontra-se encravada no escudo pré-cambriano, entrecortando os estados de Minas Gerais, Mato Grosso, São Paulo, Paraná, Santa Catarina e Rio Grande do Sul, além de abranger outros países da América do Sul, quais sejam: Uruguai, Paraguai e Argentina. Seu embasamento é constituído precipuamente por rochas cristalinas pré-cambrianas e subordinadamente por rochas eopaleozoicas afossilíferas. Essa enorme Bacia rasa é preenchida por sedimentos em sua maioria continentais e, também, alguns marinhos, com pelo menos 3600 metros de espessura; ocorrem também lavas basálticas de idade mesozoica com a espessura máxima de 1600 metros. Sobre a origem da Bacia do Paraná, Scheibe (2006, p. 6), relata que:

Com a estabilização da Plataforma Sul-Americana, entre 300 e 150 milhões de anos, na porção Oeste do Continente de Gondwana estendia-se uma grande depressão, aos poucos preenchida por sedimentos flúvio-glaciais, depois marinhos e cada vez mais continentais - praiais, flúvio-deltáicos, até desérticos: a sua consolidação originou as formações sedimentares gondwânicas da Bacia do Paraná.

No que se refere aos solos, é interessante destacar que:

Entre as bacias dos rios Timbó e Canoinhas, aparecem os solos Litólicos (solos rasos, de fertilidade natural variável [...]. No norte ocorrem os solos Latossolos Vermelho-Escuro [...]. Ao longo dos rios Iguaçu, Negro e Canoinhas ocorrem os solos Glei Húmico e Glei pouco Húmico [...]. (SANTA CATARINA, 1991, p. 9496).

Portanto, verifica-se a presença de solos dos tipos Glei Húmico e Glei pouco Húmico, ao longo dos rios Iguaçu, Negro e Canoinhas, que se caracterizam pela elevada concentração de matéria orgânica, com excesso de umidade.

No Planalto Norte Catarinense, prevalece o relevo da unidade Patamar de Mafra, com colinas baixas, em superfície regular e quase plana. Em menor proporção, mais ao Norte, está a unidade do Planalto de São Bento do Sul.

As planícies, predominantemente fluviais, ocorrem ao longo dos vales dos rios Negro e Iguaçu. Em proporção reduzida, também se manifestam em direção ao extremo norte do Estado (Campo Alegre e São Bento), onde se localiza o Planalto de São Bento do Sul. A altitude varia de 850 a 950 metros (SANTA CATARINA, 1991, p. 18).

Dentre os rios que entrecortam o território do Planalto Norte Catarinense, a ênfase recai sobre os rios Negro e Iguaçu. O rio Negro, com uma extensão de $363 \mathrm{~km}$, recebe pela margem esquerda a contribuição de 22 afluentes. Destes, os mais extensos são os rios Canoinhas $(150 \mathrm{~km})$, Preto $(102 \mathrm{~km})$, São João $(92 \mathrm{~km})$ e Negrinho $(78 \mathrm{~km})$. O rio Iguaçu, em uma extensão de $158 \mathrm{~km}$, corresponde ao limite entre os Estados do Paraná e Santa Catarina. Neste trecho, o rio Iguaçu recebe águas de doze contribuintes que se estendem pelo território do Planalto Norte Catarinense. Dentre estes contribuintes, ressalta-se o rio Jangada, com 130 $\mathrm{km}$, que também realiza o limite entre os dois estados. Outros afluentes importantes neste trecho limítrofe correspondem aos rios: Timbó $(127 \mathrm{~km})$, Paciência $(76 \mathrm{~km})$, Pintado $(46 \mathrm{~km})$ e Espingarda (44 km). 
Portanto, a partir do exame da formação hidrográfica, depreende-se que, no território do Planalto Norte Catarinense, há uma ampla rede, constituída por rios, riachos e córregos. Constata-se que essa rede se estende adequadamente, ou seja, é bem distribuída por todo o território. Todavia, verifica-se, principalmente quando ocorrem períodos de estiagem, problemas quantitativos e qualitativos nesta rede hidrográfica.

Outrossim, é assaz oportuno mencionar que, no que se refere à formação vegetal, no território do Planalto Norte Catarinense predomina a Floresta Ombrófila Mista (FOM). Essa floresta é um ecossistema originário do bioma Mata Atlântica, também conhecido como Mata de Araucárias. É uma floresta do tipo acicufoliada (folhas em forma de agulha), onde predomina a Mata das Araucárias (Araucária angustifólia) ou pinheiro do Paraná. Trata-se de uma formação resiliente às amplitudes térmicas regionais. Além da araucária ou pinheiro brasileiro, se manifestam outras espécies, dentre as quais: a erva-mate, a imbuia, as canelas, a bracatinga, os camboatás e os sassafrás. Porém, o processo extrativista, vigente desde a colonização, extraordinariamente intensificado a partir da primeira década do século XX, resultou em acentuada destruição da vegetação nativa. Por conseguinte, desta longa e intensa exploração vegetal pela indústria madeireira, visando atender ao mercado consumidor nacional e internacional, além da produção de móveis, restou, atualmente, fragmentos ou remanescentes da floresta original.

Contudo, no território do Planalto Norte Catarinense, há algumas áreas preservadas, denominadas de Reservas Biológicas ou Unidades de Conservação, sobressaindo-se a Floresta Nacional de Três Barras, abreviatura FLONA, que possui uma área de 4.385 hectares e se localiza no município de Três Barras. Além destas, existem outras Reservas Particulares de Patrimônio Natural (RPPNs), que auxiliam na preservação da biodiversidade regional.

Cabe salientar que a erva-mate, integrando a formação vegetal desse território, destaca-se pela sua histórica importância para a economia regional. Os principais municípios produtores são: Canoinhas, Itaiópolis, Irineópolis e Major Vieira.

Por sua vez, segundo a metodologia de Köppen, o clima é mesotérmico, predominantemente subtropical úmido, algumas vezes sendo superúmido, com estações relativamente bem definidas e temperatura média anual entre $18^{\circ} \mathrm{C}$ a $20^{\circ} \mathrm{C}$, ocorrendo geadas durante a estação do inverno. No verão, a temperatura é branda, com a média oscilando em torno de $22^{\circ} \mathrm{C}$, porém, é comum a ocorrência de temperaturas superiores a $30^{\circ} \mathrm{C}$. A altitude média é de 840 metros. A umidade relativa do ar (média anual) é de aproximadamente 75\%, com uma precipitação pluviométrica média anual de $1700 \mathrm{~mm}$ (SANTA CATARINA, 1991).

De todo o exposto anteriormente, constata-se que a formação geológica apresenta solos com elevada concentração de matéria orgânica, ao passo que o relevo caracteriza-se por colinas baixas, em superfície regular e quase plana com planícies predominantemente fluviais; verifica-se, também, que a formação hidrográfica, constituída por ampla rede de rios, riachos e córregos, se apresenta relativamente bem distribuída por todo o território; além disso, ocorre clima subtropical, com temperaturas amenas e bons índices de precipitação pluviométrica. 


\title{
EXTRATIVISMO NO TERRITÓRIO DO PLANALTO NORTE CATARINENSE
}

Ao aplicar o enfoque metodológico adotado neste artigo, mediante análise integrada dos aspectos históricos e das características físico-naturais pertinentes ao território do Planalto Norte Catarinense, obtém-se um panorama que explica a profunda intensificação do processo extrativista vegetal, a partir da segunda década do século XX, no território sob análise.

Contudo, é preciso salientar que, outrora, desde os primórdios do povoamento até meados do século XIX, o extrativismo decorreu da exploração dos recursos naturais para fins de subsistência dos moradores pobres que habitavam os bairros rurais.

É possível dividir em fases distintas a história da exploração madeireira e do desmatamento da floresta com araucária. Até o ano de 1870, a exploração deu-se de forma manual, sem o emprego de máquinas, praticamente não afetando a área original da floresta de araucárias. Isto decorreu do modo de vida da população pobre - os caboclos - do planalto norte catarinense, que dependiam, essencialmente, dos recursos extraídos das florestas, ricas em variedades vegetais e animais. Dentre esses elementos, destacavam-se a semente do pinheiro araucária (pinhão) e, principalmente, a erva-mate, além da madeira utilizada para atender a diferentes propósitos (CARVALHO, 2010).

Entretanto, consoante analisado nos aspectos históricos, no início do século XX, a Brazil Railway Company, companhia responsável pela construção da ferrovia São Paulo-Rio Grande, constituiu uma subsidiária, a Southern Brazil Lumber and Colonization Company, visando exercer o direito de explorar as áreas de terras adjacentes à linha-tronco da ferrovia (TOMPOROSKI, 2006). Neste ínterim, é plausível indagar: o que motivou o capital estrangeiro a instalar, especificamente no Planalto Norte Catarinense, a maior serraria da América do Sul? Conforme descrito na seção das características físico-naturais, no território do planalto norte catarinense predomina a floresta de araucárias. Deste fato, decorre que um dos objetivos da companhia Lumber consistiu em explorar, através do extrativismo de produção, as inesgotáveis reservas de madeira, provenientes da Mata de Araucárias.

\begin{abstract}
A região do atual planalto norte catarinense [...] foi onde a Lumber instalou a sua maior serraria e onde estavam concentrados os seus maiores investimentos em maquinário e terras. A empresa se beneficiou de um meio natural com inegáveis vantagens para o desenvolvimento dos negócios madeireiros. Em primeiro lugar, a existência da imponente floresta com araucária que havia no local, com pinheiros enormes, cujo porte hoje em dia é raríssimo na região da araucária como um todo. No sub-bosque, havia ainda uma grande quantidade de imbuia (Ocotea porosa), madeira de lei bastante resistente às intempéries [...] (CARVALHO, 2010, p. 201).
\end{abstract}

Dentre as características físico-naturais, o relevo do planalto norte catarinense também contribuiu para o processo extrativista deflagrado pela Lumber Company.

\footnotetext{
Outra característica natural que favoreceu os negócios da companhia foi o fato da mesma ter comprado terras em áreas predominantemente de planícies. Isso significou uma série de vantagens em termos operacionais, desde a construção e uso de ferrovias particulares, muito mais baratas em terrenos planos, até o próprio corte das enormes toras e arrasto das mesmas até as serrarias [...] (CARVALHO, 2010, p. 202).
}

A formação hidrográfica do território sob análise, constituída por ampla rede de rios, também favoreceu o processo extrativista da Lumber Company, a qual utilizou amplamente o 
transporte fluvial pelos rios Negro e Iguaçu. Para tanto, adquiriu dois vapores, o "Três Barras" e o "Porto Velho" (TOMPOROSKI, 2006, p. 27).

Com o intuito de proporcionar uma percepção acerca das dimensões do processo extrativista desencadeado pela Lumber Company, cabe analisar o processo de concentração fundiária desencadeado pela companhia. No ano em que iniciou a extração na região do atual Planalto Norte Catarinense, a empresa possuía 225.000 hectares de terras povoadas com araucárias primárias. Este montante fora adquirido pela empresa junto a proprietários da região, os quais vinham promovendo a retirada da população cabocla que ocupava aquele território havia gerações. Além dos 225.000 hectares, a empresa recebera cerca de nove quilômetros às margens da estrada de ferro, parte do contrato de concessão. $O$ trecho da linha férrea que cortou o Planalto Norte Catarinense, ligando União da Vitória (PR) e a cidade portuária de São Francisco do Sul (SC) possuía aproximadamente 320 quilômetros de extensão, correspondendo a uma área total de cerca de 2800 quilômetros quadrados, com cerca de $90 \%$ em terras do PNC.

Com base nesses dados e considerando que o território do Planalto Norte Catarinense abrange atualmente uma área de $11.041,365 \mathrm{~km}^{2}$ (onze mil, quarenta e um vírgula trezentos e sessenta e cinco quilômetros quadrados), verifica-se que a área de terras comprada pela Lumber Company, há mais de um século, representa aproximadamente 40\% (quarenta por cento) da atual configuração territorial do Planalto Norte Catarinense. Em termos mais concretos, é algo verdadeiramente espantoso que uma empresa privada, controlada pelo capital estrangeiro, detivesse a propriedade e a posse de tamanha área de terras, cobertas por florestas nativas de Araucárias.

\section{CONSIDERAÇÕES FINAIS}

Constata-se, a partir da análise dos aspectos históricos e de características físiconaturais do Planalto Norte Catarinense, que o extrativismo de produção, desencadeado pelos interesses econômicos do capital estrangeiro, subtraiu, nas primeiras décadas do século XX, enorme parcela da riqueza natural deste território. Durante um período de aproximadamente trinta anos, iniciando-se em 1910 e estendendo-se até sua estatização, no ano de 1940, a Lumber Company gerou um impacto considerável no ecossistema do território, ceifando milhões de árvores, dentre as quais, pinheiros araucárias, imbuias, canelas pretas, cedros e cabriúvas. Ademais, é preciso considerar que, mesmo após a estatização, em 1940, a Lumber Company continuou operando e extraindo árvores nativas, cessando suas atividades somente em meados na década de 1950 .

O extrativismo de produção praticado pela Lumber Company gerou grande impacto sobre a Mata de Araucárias, mas, é necessário compreender que, em decorrência de diversos fatores, inerentes ao processo histórico, a companhia explorou uma reduzida parcela do potencial extrativista de que dispunha. Presumindo a ausência de restrições ao processo extrativista, e a inexistência de limitações à demanda do mercado consumidor, hipóteses que propiciariam a realização plena do potencial extrativista, a exaustão das reservas controladas pela empresa. 
Não obstante o término das atividades operacionais da Lumber Company, o processo extrativista de produção, intensificado por esta companhia, permaneceu instaurado no território, nas décadas subsequentes.

A partir do final da década de 1960, em substituição da araucária, deu-se o fenômeno da introdução de novas espécies de vegetação, árvores exóticas, como o Pinus illiottii, e, desde então, essas árvores têm sido destinadas como fonte primária de matéria-prima para as indústrias de celulose, papel e móveis.

A introdução do pinus resultou na continuidade do processo de extrativismo de produção. Apesar de atenuar a exploração das matas nativas, remanescentes da floresta de araucárias, a utilização desta espécie exótica ocasionou outras perturbações ao processo de desenvolvimento sustentável do território. A disseminação dos plantios de espécies vegetais exóticas, na forma de monocultura, reduz as áreas que poderiam ser utilizadas para diversificação produtiva. Ainda há o agravante quanto à dispersão destes plantios, pois, além das grandes fazendas produtoras, em sua maioria de propriedade das indústrias de papel celulose, estímulos variados fizeram com que a iniciativa particular, pequenos produtores, também adotassem o pinus em detrimento de outras culturas. No que tange ao aspecto econômico, citando apenas uma das implicações, ocorre a ampliação do ciclo econômico da produção, pois, enquanto culturas diversificadas possuem período de plantio e colheita contados em meses, os reflorestamentos de pinus demandam anos para obtenção do retorno de investimento, prejudicando, devido a baixa rotatividade, a geração de emprego e renda. A título de exemplo, no estado do Paraná, segundo estimativas realizadas no ano de 2004, os plantios de reflorestamentos com espécies exóticas totalizavam 552.973 hectares (quinhentos e cinquenta e dois mil, novecentos e setenta e três hectares), o que equivale a 5.529,73 quilômetros quadrados (cinco mil, quinhentos e vinte e nove vírgula setenta e três quilômetros quadrados) (CARVALHO, 2010, apud CASTELLA e BRITEZ, 2004, p.19).

Portanto, o processo extrativista de produção, deflagrado pelo capital estrangeiro nas primeiras décadas do século XX, ainda hoje exerce influência sobre o desenvolvimento do território do Planalto Norte Catarinense.

Diante deste cenário histórico, ambiental e econômico, advêm desafios ingentes e urge elaborar e implementar estratégias que viabilizem a realização do potencial latente dos ativos materiais e imateriais do território, com o intuito de agregar valor, renda e desenvolvimento sustentável, enfim, promover o desenvolvimento regional, que, em última instância, deve considerar o zelo pelos bens naturais e, precipuamente, a melhoria da qualidade de vida das pessoas que vivem no território do Planalto Norte Catarinense.

Dentre as estratégias mais promissoras visando o desenvolvimento territorial, cabe destacar aquelas que privilegiam as potencialidades imanentes aos aspectos históricos e às características físico-naturais do território sob análise. Dentre as possibilidades, é possível vislumbrar a revitalização do turismo histórico amparado nos episódios da Guerra do Contestado (1912-1916) e a exploração sustentável da erva-mate e dos remanescentes da Floresta Ombrófila Mista (FOM). Neste sentido, importantes pesquisas desenvolvidas (e em desenvolvimento) no âmbito do Programa de Mestrado em Desenvolvimento Regional (PMDR), da Universidade do Contestado, indicam estratégias para viabilizar a utilização do potencial destes ativos naturais, em prol do desenvolvimento do território do Planalto Norte Catarinense. 


\section{REFERÊNCIAS}

CARVALHO, M. M. X. Uma grande empresa em meio à floresta: a história da devastação da floresta com araucária e a Southern Brazil Lumber and Colonization (1870-1970). Tese (Doutorado em História). Florianópolis: Universidade Federal de Santa Catarina, 2010.

CASTELlA, P. R.; BRITEZ, R. M. A floresta com araucária no Paraná: conservação e diagnóstico dos remanescentes florestais. Fundação de Pesquisas Florestais do Paraná. Brasília: Ministério do Meio Ambiente, 2004.

LOCZY, L.; LADEIRA, E. A. Geologia estrutural e introdução à geotectônica. São Paulo: Edgard Blücher; Rio de Janeiro: Conselho Nacional de Desenvolvimento Científico e Tecnológico, 1980.

MACHADO, P. P. Lideranças do Contestado: a formação das chefias caboclas (19121916). Campinas, SP. Editora da Unicamp, 2004.

MELlo E SOUZA, A. C. Os Parceiros do Rio Bonito: estudos sobre o caipira paulista e a transformação dos seus meios de vida. São Paulo: Duas Cidades, 2001.

SANTA CATARINA. Secretaria de Estado de Coordenação Geral e Planejamento SEPLAN. Subsecretaria de Estudos Geográficos e Estatísticos. Atlas Escolar de Santa Catarina. Florianópolis, 1991.

SCHEIBE, L. F. O Sistema Aquífero Integrado Guarani-Serra Geral (SAGSA) em Santa Catarina: uma contribuição para a Educação Ambiental. (PowerPoint) Laboratório de Análise Ambiental. Departamento de Geociências - UFSC - UNOESC. São Miguel do Oeste, 22/09/06.

SUPRINYAK, C. E. O Mercado de Animais de Carga no Centro-Sul do Brasil Imperial: Novas Evidências. Est. econ., São Paulo, v. 38, n. 2, p. 319-347, abr./jun. 2008.

TOMPOROSKI, A. A. “O pessoal da Lumber!” Um estudo acerca dos trabalhadores da Southern Brazil Lumber and Colonization Company e sua atuação no planalto norte de Santa Catarina, 1910 - 1929. Florianópolis. Dissertação (Mestrado em História). Universidade Federal de Santa Catarina. Florianópolis, 2006.

O polvo e seus tentáculos. A Southern Brazil Lumber and Colonization Company e as transformações impingidas ao planalto contestado, 1910-1940. Tese (Doutorado em História). Florianópolis: UFSC, 2013.

Os costumes no planalto catarinense: dos embates no movimento sertanejo do Contestado à luta contra as imposições do capital estrangeiro (1912-1919). Revista Brasileira de História \& Ciências Sociais - RBHCS, v. 7, n. 14, p. 27-56, dez. 2015.

Artigo recebido em: 21/06/2016

Artigo aprovado em: 12/07/2016 